\title{
Injury mortality among children and teenagers in the United States, 1993
}

\author{
Lois A Fingerhut, Joseph L Annest, Susan P Baker, Kenneth D Kochanek, Elizabeth \\ McLoughlin
}

National Center for
Health Statistics,
Centers for Disease
Control and
Prevention,
Hyattsville, Maryland,
USA
LA Fingerhut
KD Kochanek

National Center for Injury Prevention and Control, Centers for Disease Control and Prevention, Atlanta, Georgia, USA

JL Annest

Center for Injury Research and Policy, The Johns Hopkins University, Baltimore, Maryland, USA

SP Baker

San Francisco Injury Center for Research and Prevention, California, USA

E McLoughlin

Correspondence to: Ms Lois A Fingerhut, Special Assistant for Injury Epidemiology, Office of Analysis, Epidemiology and Health Promotion, US Public Health Service and Prevention, 6525 Belcrest Road, Room 750 Hyattsville, MD 20782, USA.
With this edition of Injury Prevention, we are pleased to begin the annual submission of injury mortality rates for children and teenagers in the United States. The 1993 cause specific mortality data are from the National Center for Health Statistics (NCHS) of the Centers for Disease Control and Prevention, and are based on information reported on death certificates and filed in the 50 states and the District of Columbia.

The tabular data conventions we have adopted in the accompanying table were arrived at after long and significant deliberations, and are the product of a collaborative effort in the injury control community in the United States ${ }^{12}$ with assistance from the National Center for Injury Prevention and Control and NCHS. Standard definitions of external causes of injury mortality (and morbidity) are crucial for improving comparability across populations. In addition, standardizing definitions will facilitate the dissemination of data and other resources needed for the effective implementation of injury prevention programs.

The mortality data shown in the following table are presented by the two axes of the external cause of injury and poisoning codes in the International Classification of Diseases, 9th revision (ICD-9 E-codes): (1) mechanism or cause of death and (2) intent of injury or manner of death. This method of data presentation more effectively presents the impact of injury mortality on children by focusing primarily on the mechanism of the injury, and secondarily on the intent. In previous tabulations of data, many of the external causes of injury such as suffocation, poisoning, and firearms have often been shown only for the 'unintentional' category. As shown in the table, this can significantly underestimate the magnitude of the problem caused by these injuries.

\section{Data highlights}

In 1993, 20945 children and teenagers 0-19 years of age died as a result of an injury at a rate of 28.3 per 100000 population. Across these ages, motor vehicle traffic crashes and firearm injuries were the two leading causes of death. Among infants, the death rate due to suffocation was higher than any other single cause of injury, although homicide accounted for $26 \%$ of injury deaths. For children 1-4 years, death rates associated with motor vehicle traffic crashes (occupant and pedestrian fatalities), fires/flames, and drowning were among the highest. At ages 5-9 and 10-14 years, death rates due to motor vehicle traffic crashes lead other causes. In these age groups, the children were occupants, pedestrians, and bicyclists. For teenagers ages 15-19, death rates due to motor vehicle traffic crashes (primarily occupant fatalities) and firearm injuries were similar, responsible for about $80 \%$ of all injury deaths in that age group. Homicide and suicide accounted for $45 \%$ of injury mortality among teenagers.

1 Berenholz G. Draft recommendations report of standard E-code groupings. (Unpublished report.) Lexington, MA: Berenholz Consulting Associates, July 1995.

2 McLoughlin E, Fingerhut L, Weiss H, Annest L. A proposed mechanism/intent matrix for presenting $E$-coded data. (Unpublished report) Atlanta GA: National Center for Injury Prevention and Control, July 1995.

Editor's note: this contribution marks the first of a new series of annual reports of this kind. Our hope is that alongside such critically important statistics from the United States, we will be able to publish similar data from other countries. International comparisons of this kind are vital to the promotion of injury prevention and the new classification system developed by Fingerhut and her colleagues is a major step towards making the data still more useful. 


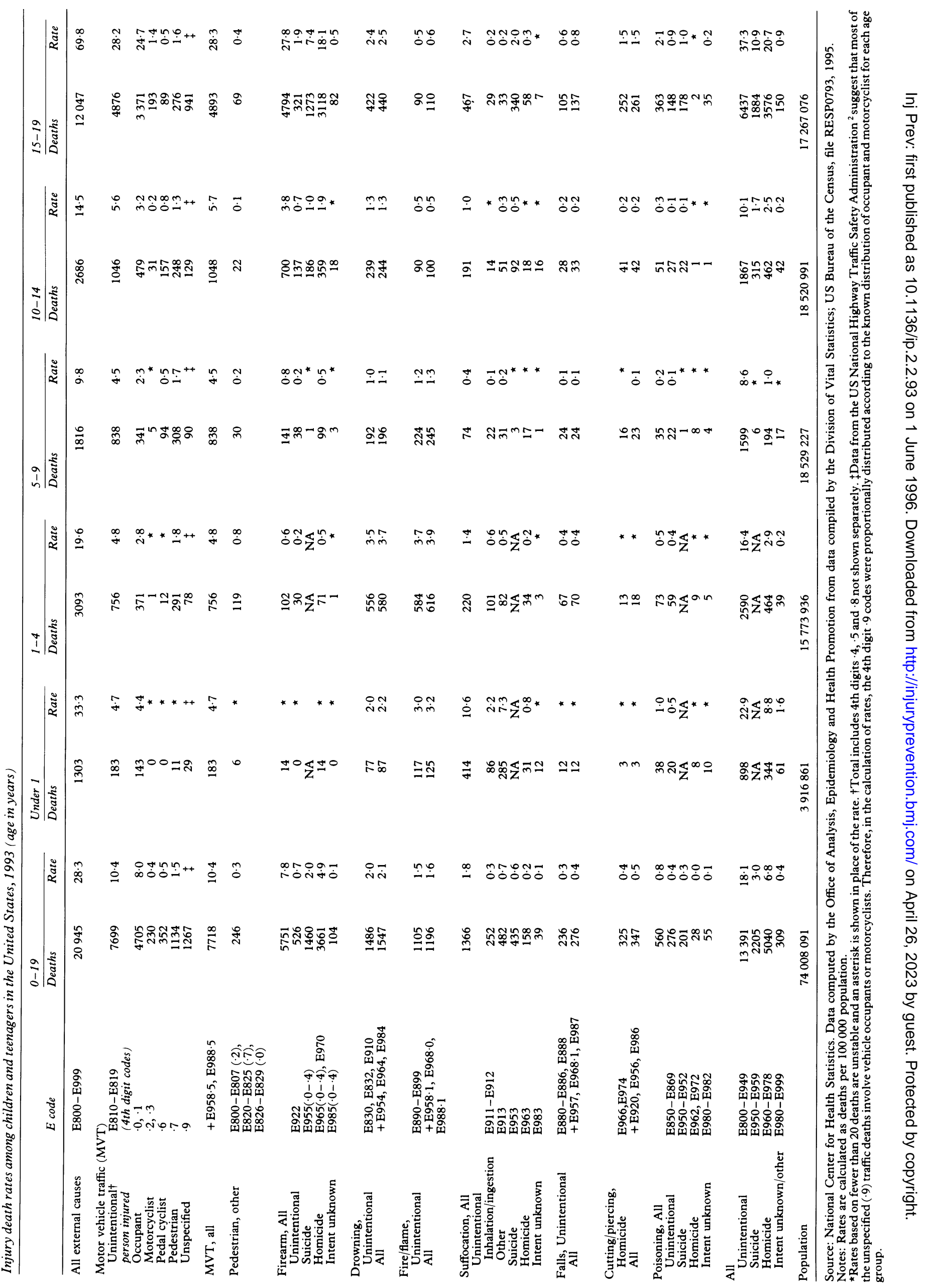

